\title{
UJI PEMBERIAN KOMPOS TANDAN KOSONG SAWIT DANNPK 16:16:16 PADA PEMBIBITAN KELAPA SAWIT(Elaeis guineensis Jacq.) MAIN NURSERY DENGAN MEDIA SUB SOIL ULTISOL
}

\author{
The Test of the Composites of Saily and Sand NPK16:16:16 on Sewing Palm Oil \\ (Elaeis guineensis Jacq.) Main Nurserywith Sub Soil Ultisol Media
}

\author{
Aminullah, T. Rosmawati dan Sulhaswardi \\ Program Studi Agroteknologi, Fakultas Pertanian, Universitas Islam Riau \\ Jl. Kaharuddin nasution No.113 Pekanbaru 28284 Riau \\ telp:0761-72126 ext.123, fax: 0761-674681 \\ [Diterima: Oktober 2017; Disetujui: Desember 2017]
}

\begin{abstract}
The purpose of this research is to know the influence of compost TKKS and NPK 16:16:16 on the breeding of oil palm (Elaeis guineensis Jacq.) in Main Breeding with Sub Soil Ultisol Media. This research has been conducted in the field of Agriculture Faculty of the Islamic University of Riau. for 4 months, starting from April to August 2017. The design used in this research is Factorial Random Design (RAL) consisting of two factors, the first factor is Giving of empty palm fruit bunch compost (Factor K) consisting of 4 levels ie not giving empty bunches of palm oil (K0), giving compost of oil palm empty bunch 90 gr/plant (K1), 180 gr/plant (K2) and 270 gr/plant (K3), and NPK 16:16:16 Fertilizer (Factor P) consisting of 4 levels ie not giving fertilizer (P0), NPK 16:16:16 $15 \mathrm{~g} / \mathrm{plant}(\mathrm{P} 1), 30 \mathrm{gr} / \mathrm{plant}(\mathrm{P} 2), 45 \mathrm{gr} /$ plant (P3) and $60 \mathrm{gr} / \mathrm{plant}(\mathrm{P} 4)$. The parameters observed in this study were the increase of plant height $(\mathrm{cm})$, the increase of the number of stem (strands), the length of the longest stem length $(\mathrm{cm})$, the increase of girth $(\mathrm{cm})$, the number of root root (root) and root length $(\mathrm{cm})$. The result of the research showed that the interaction of TKKS compost and NPK 16:16:16 fertilizer gave a significant effect on the plant height increase, the increase of midrib, the length of the longest bark and the increase of girth. Combination of best treatment on compost TKKS $270 \mathrm{~g} / \mathrm{plant}$ and NPK 16:16:16 $60 \mathrm{~g} /$ plant (K3P4) fertilizer. The main effect of TKKS compost and NPK 16:16:16 fertilizer gave a significant effect on all parameters in the range of plant height, the increase of midrib, the length of the longest stem, the increase of girth, the number of root roots and the longest root length. With the best treatment is the compost TKKS $270 \mathrm{~g} / \mathrm{plant}$ (P3) and fertilizer NPK 16:16:16 60 g/plant (P4).
\end{abstract}

Keywords: Kelapa Sawit, Main Nursery, Ultisol

\begin{abstract}
ABSTRAK
Tujuan dari penelitian ini adalah untuk mengetahui pengaruh kompos TKKS dan NPK 16:16:16 terhadap pembibitan kelapa sawit (Elaeis guineensis jacq.) main nurserydengan media sub soil ultisol. Penelitian ini telah dilakukan di Fakultas Pertanian Universitas Islam Riauselama 4 bulan, mulai dari bulan April hingga Agustus 2017. Desain yang digunakan dalam penelitian ini adalah Rancangan Acak Kelompok (RAL) yang terdiri dari dua faktor, faktor pertama adalah pemberian kompos tandan kosong (Faktor K) yang terdiri dari 4 level yaitu tanpa pemberian tandan kosong kelapa sawit (K0), pemberian kompos tandan kosong kelapa sawit 90 gr / tanaman (K1), 180 gr / tanaman (K2) dan $270 \mathrm{gr} /$ tanaman (K3), dan NPK 16:16:16. Pupuk NPK ( Faktor P) terdiri dari 4 taraf yaitu tanpa pemberian pupuk NPK 16:16:16 (P0), $15 \mathrm{~g} /$ tanaman (P1), $30 \mathrm{gr} / \operatorname{tanaman}(\mathrm{P} 2)$, $45 \mathrm{gr} / \operatorname{tanaman}(\mathrm{P} 3)$ dan $60 \mathrm{gr} / \operatorname{tanaman}(\mathrm{P} 4)$. Parameter yang diamati dalam penelitian ini adalah pertambahan tinggi tanaman $(\mathrm{cm})$, pertambahan jumlah daun (helai), pertambahan panjang pelepah terpanjang $(\mathrm{cm})$, pertambahan lilit batang $(\mathrm{cm})$, jumlah akar primer(buah) dan panjang akar(cm).Hasil penelitian menunjukkan bahwa pertambahan tinggi tanaman, pertambahan jumlah
\end{abstract}


pelepah, pertambahan panjang pelepah terpanjang dan pertambahan lilit batang. Kombinasi perlakuan terbaik pada pemberian kompos tandan kosong kelapa sawit $270 \mathrm{gr} / \mathrm{tanaman}$ dan pupuk NPK 16:16:16 60 gr/tanaman (K3P4).Pengaruh utama pemberian kompos tandan kosong kelapa sawit memberikan pengaruh nyata terhadap semua parameter yang dimati dengan perlakuan terbaik yaitu pemberian kompos tandan kosong kelapa sawit 270 gr/tanaman (K3).Pengaruh utama pemberian pupuk NPK 16:16:16 memberikan pengaruh nyata terhadap semua parameter yang dimatidengan perlakuan terbaik yaitu pemberian pupuk NPK 16:16:16 60 gr/tanaman (P4).

\section{Kata kunci: Kelapa Sawit, Pembibitan Utama, Ultisol}

\section{PENDAHULUAN}

Kelapa sawit merupakan komoditi yang penting dalam mendorong perekonomian Indonesia dan Riau. Sebagai penghasil devisa negara kelapa sawit merupakan salah satu komoditi yang memberikan sumbangan yang sangat berarti dalam peningkatan pertumbuhan ekonomi.

Berdasarkan data luasan lahan lahan kebun kelapa sawit yang di publikasikan oleh badan pusat statistik provinsi Riau dan umur produktif tanaman kelapa sawit dapat dibayangkan berapa banyak lahan yang akan direplanting dimasa yang akan datang. Besarnya luas areal kebun kelapa sawit yang akan di remajakan tentu membutuhkan bibit berkualitas dalam jumlah yang banyak.

Untuk mendapatkan bibit yang baik dan sehat, aplikasi dan dosis pemupukan harus dilakukan.Pemilihan pupuk yang tepat adalah salah satu langkah yang perlu diperhatikan agar pembibitan yang dilakukan nantinya berhasil.Pupuk yang diberikan pada bibit berdasarkan sifat senyawanya ada dua jenis, yaitu pupuk organik dan pupuk anorganik. Salah satu pupuk organik yang dapat diberikan pada tanaman adalah pupuk kompos yang berasal dari tandan kosong kelapa sawit. .

Tandan Kosong Kelapa Sawit (TKKS) merupakan limbah padat hasil pabrik kelapa sawit yang jumlahnya cukup besar, yaitu sekitar 6 juta ton per tahun (Purnama. 2015)

Fauzi et al., (2002) mengemukakan bahwa pupuk tandan kosong memiliki beberapa sifat yang menguntungkan antara lain: memperbaiki sifat tanah seperti struktur tanah, menambah ketersediaan hara bagi tanah, membantu kelarutan unsur-unsur hara yang diperlukan bagi pertumbuhan tanaman, bersifat homogen dan mengurangi resiko sebagai pembawa hama tanaman, selain itu tandan kosong kelapa sawit juga merupakan pupuk yang tidak mudah tercuci oleh air.

Pemanfaatan tanah lapisan bawah (subsoil) akan menjadi alternatif untuk menggantikan peran topsoil sebagai media tanam untuk bibit tanaman perkebunan di pembibitan. Hal ini disebabkan subsoil relatif lebih banyak tersedia dan mudah dijumpai dalam jumlah yang cukup besar di lapangan, di bandingkan dengan topsoil. Penggunaan tanah lapisan bawah ini tentu akan menjadi tantangan karena secara fisik dan kimia tanah ini relatif kurang subur dan miskin unsur haranya, serta mengandung bahan organik yang sangat rendah sehingga memerlukan penambahanbahanbahanyangdapat memperbaikisifat fisik dankimia tanah tersebut.

Kandungan bahan organik yang rendah ini dapat diatasi dengan pemberian pupuk organik misalnya pupuk kompos atau bahan organik lainnya, sedangkan rendahnya kandungan dan ketersediaan hara dapat diperbaiki dengan pemberian pupuk NPK.

Pupuk NPK merupakan pupuk majemuk yang sangat baik untuk pertumbuhan dan produksi tanaman, pupuk NPK memiliki kandungan nitrogen, fosfor dan kalium yang cukup tinggi.

Penelitian ini bertujuan untuk Untuk mengetahui Pengaruh Interaksi pupuk kascing danUrin sapi pada Pembibitan Kakao.

\section{METODE PENELITIAN}

Penelitian initelahdilaksanakan di Kebun Percobaan Fakultas Pertanian Universitas Islam Riau, Jalan Kaharuddin Nasution Km 11 No 113, Kelurahan Air digin, Kecamatan Bukit Raya, Kota Pekanbaru.penelitiandilakuakn 
selama empat bulan yang terhitung mulai dari bulan Aprilsampai dengan Agustus 2017

Bahan-bahan yang akan digunakan dalam penelitian ini adalah bibit kelapa sawit varietas Marihat (lampiran 2) yang berumur \pm 6 bulan, tandan kosong kelapa sawit, Pupuk NPK Mutiara 16:16:16, EM4, gula merah, dedak padi, Dithane M-45, Decis dan polybag 40 x 50 $\mathrm{cm}$. Alat yang digunakan adalah cangkul, pisau, ember, sprayer, timbangan analitik, tali, hansprayer, gembor, kamera, meteran dan alat tulis.

Rancangan yang digunakan dalam penelitian ini adalah Rancangan Acak Lengkap (RAL) faktorial yang terdiri dari dua faktor, faktor pertama adalah Pemberian kompos tandan kosong kalapa sawit (Faktor K) dan pemberian Pupuk NPK 16:16:16 (Faktor P). Pemberian kompos tandan kosong kalapa sawit terdiri dari 4 taraf perlakuan, dan pemberian Pupuk NPK 16:16:16 terdiri dari 4 taraf sehingga terdapat 16 kombinasi perlakuan dengan 3 ulangan maka ada 48 unit percobaan.Masing-masing unit terdiri dari 4 tanaman, dan 2 tanaman dijadikan sebagai sampel, sehingga keseluruhan tanaman 192 tanaman.

Pelaksanaan Penelitian yang dilakukan adalah Persiapan Lahan dan penyusunan polybag, Pengisian polybag, Persiapan bibit kelapa Sawit, Persiapan Bahan Perlakuan, Penyusunan polybag, Pemasangan Label, Pemberian Perlakuan, Pemindahan bibit ke polybag besar (main-nursery), dan Pemeliharaan. Parameter yang diamati adalah Pertambahan Tinggi Tanaman (cm), PertambahanJumlah Daun (helai), Pertambahanlilit Batang $(\mathrm{cm})$, Jumlah Akar primer (akar), Panjang akar terpanajng $(\mathrm{cm})$.

\section{HASIL DAN PEMBAHASAN}

\section{Pertambahan Tinggi Tanaman $(\mathrm{cm})$}

Hasil pengamatan terhadap pertambahan tinggi tanaman kelapa sawit dengan pemberian kompos tandan kosong kelapa sawit dan pupuk NPK 16:16:16 setelah dilakukan analisis sidik ragammemperlihatkan bahwa pemberian kompos tandan kosong kelapa sawit dan NPK secara interaksi tidak berpengaruh nyata terhadap pertambahan tinggi tanaman kelapa sawit pada pengamatan 1 dan 2 bulan setelah pindah tanam. Namun berpengaruh nyata pada pengamatan 3 bulan setelah pindah tanam.Sedangkan pengaruh utama dari masing masing perlakuan memberikan pengaruh yang nyata terhadap pertambahan tinggi tanaman kelapa sawit.Rata-rata pertambahan tinggi tanaman kelapa sawit dapat dilihat pada tabel 1 .

Tabel 1.Rata-rata tinggi tanaman kakao dengan perlakuan kascing dan urin sapi.

\begin{tabular}{cccccc}
\hline \multirow{2}{*}{$\begin{array}{c}\text { KOMPOS } \\
\text { (gr/tanaman) }\end{array}$} & $\mathrm{P} 1$ & $\mathrm{P} 2$ & $\mathrm{P} 3$ & \multirow{2}{*}{ Rata-rata } \\
\cline { 2 - 5 } & $(15)$ & $(30)$ & $(45)$ & $\mathrm{P} 4$ & $(60)$ \\
\hline K0 $(0)$ & $32,83 \mathrm{e}$ & $41,00 \mathrm{de}$ & $41,17 \mathrm{de}$ & $44,33 \mathrm{bcd}$ & $39,83 \mathrm{~b}$ \\
K1 $(90)$ & $41,83 \mathrm{~cd}$ & $41,00 \mathrm{de}$ & $43,67 \mathrm{~cd}$ & $45,67 \mathrm{abc}$ & $43,04 \mathrm{~b}$ \\
K2 $(180)$ & $46,17 \mathrm{abc}$ & $44,83 \mathrm{bc}$ & $45,67 \mathrm{abc}$ & $50,33 \mathrm{abc}$ & $46,75 \mathrm{a}$ \\
K3 $(270)$ & $42,33 \mathrm{~cd}$ & $47,33 \mathrm{abc}$ & $52,67 \mathrm{ab}$ & $53,83 \mathrm{a}$ & $49,04 \mathrm{a}$ \\
\hline Rata-rata & $40,79 \mathrm{c}$ & $43,54 \mathrm{bc}$ & $45,79 \mathrm{ab}$ & $48,54 \mathrm{a}$ & \\
\hline \multicolumn{7}{c}{$\mathrm{KK}=6,50 \%$ BNJ N\&P=3,22BNJ N\&P=8,83 }
\end{tabular}

Angka-angka pada kolom dan baris yang diikuti huruf kecil yang sama tidak berbeda nyata menurut uji lanjut BNJ pada taraf $5 \%$.

Pada tabel 2 menunjukkan bahwa interaksi pemberian kompos tandan kosong kelapa sawit dan pupuk NPK 16:16:16 berpengaruh nyata terhadap pertambahan tinggi bibit kelapa sawit pada umur 3 bulan setelah pindah tanam. Diamana kombinasi perlakuan K3P4 (Kompos tandan kosong kelapa sawit 270 gr/tanaman dan Pemberian pupuk NPK
16:16:16 60 gr/tanaman) dengan Rata-rata pertambahantinggi tanaman 53,83 cm, kombinasi perlakuan K3P4 tidak berbeda nyata dengan kombinasi perlakuan K3P3 yaitu 52,67 $\mathrm{cm}$, K3P2 yaitu $47,33 \mathrm{~cm}, \mathrm{~K} 2 \mathrm{P} 4$ yaitu 50,33 $\mathrm{cm}, \mathrm{K} 2 \mathrm{P} 3$ yaitu $45,67 \mathrm{~cm}, \mathrm{~K} 2 \mathrm{P} 1$ yaitu $46,17 \mathrm{~cm}$ dan K1P4 yaitu 45,67 cm. tetapi berbeda nyata dengan perlakuan lainnya. Sedangkan Pertambahan tinggi tanaman terendah didapat 
dari kombinasi perlakuan K0P1 (Kompos tandan kosong kelapa sawit 0gr / tanaman dan Pemberian pupuk NPK 16:16:16 15gr/tanaman) dengan Rata-rata pertambahan tinggi tanaman kelapa sawit $32.83 \mathrm{~cm}$. perlakuan K0P1 tidak berbeda nyata dengan perlakuan K0P2 yaitu $41.00 \mathrm{~cm}, \mathrm{~K} 0 \mathrm{P} 3$ yaitu $41.17 \mathrm{~cm}$ dan K1P2 yaitu 41.00. tetapi berbeda nyata dengan kombinasi perlakuan lainnya.

Pertambahan tinggi tanaman kelapa sawit pada perlakuan K3P4 lebih baik dari perlakuan lainnya karena kompos tandan kosong kelapa sawit mampu memperbaiki kesuburan tanah (kimia) seperti menyumbangkan unsur hara kedalam tanah baik mikro maupun makro. Sutarta dan Darnoko, (2005) unsur hara yang terkandung didalam kompos tandan kosong kelapa sawit adalah : Makro $\mathrm{N}=0.34 \%, \mathrm{P} 2 \mathrm{O}=0.13 \%$, $\mathrm{K} 2 \mathrm{O}=0.51 \%, \mathrm{Ca}=0.74 \%$ dan $\mathrm{Mg}=0.14 \%$ Mikro $\mathrm{Fe}=441 \mathrm{ppm}, \mathrm{Mn}=91 \mathrm{ppm}, \mathrm{Cu}=5 \mathrm{ppm}$ dan $\mathrm{Zn}=32 \mathrm{ppm}$. Selain memperbaiki sifat kimia tanah kompos tandan kosong kelapa sawit juga dapat memperbaiki sifat fisika tanah, seperti meningkatkan kemampuan tanah menyerap air, memperbaiki agregat tanah, poripori dan aerase tanah sehingga difusi $\mathrm{O}_{2}$ kedalam tanah meningkat.Pemberian kompos tandan kosong kelapa sawit juga memperbaiki biologi tanah seperti meningkatkan aktifitas mikro organisme tanah sebagai decomposer.

Selain kompos tandan kosong kelapa sawit pupuk NPK juga mempengaruhi tinggi tanaman, karena pupuk NPK merupakan salah satu pupuk yang cepat tersedia dan langsung dimanfaatkan oleh tanaman sehingga dapat memacu petumbuhan tanaman serta meningkatkan pertumbuhan tanaman (Anonimus, 2003).Untuk mengetahui lebih jelasnya pertambahan tinggi tanaman kelapa sawit dapat dilihat pada gambar berikut.

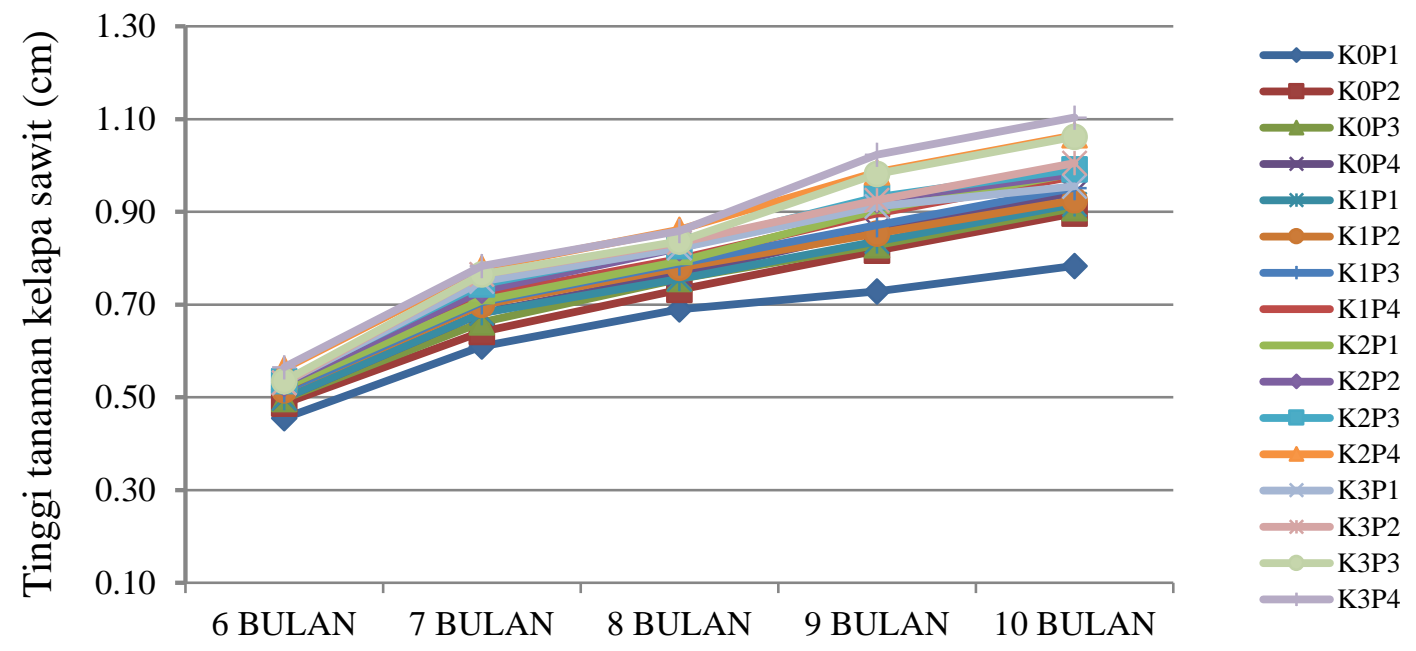

Gambar 1. Pertambahan tinggi tanaman kelapa sawit dengan pemberian kompos tandan kosong kelapa sawit dan pupuk NPK 16:16:16

Pada Gambar 1. Terlihat bahwa pada bulan pertama setelah pindah tanam Rata-rata pertambahan tinggi tanaman meningkat tajam.Hal ini diduga karena pengaruh dari penukaran media tanam dari polybag $3 \mathrm{~kg}$ menjadi 6 kg.dengan bertambah nya volume media tentu akan mendorong perkembangan akar, hal ini tentu akan memperluas jangkauan akar dalam penyerapan air dan kandungan unsur hara sehingga metabolisme tanaman akan berjalan baik. mempunyai sifat fisik yang baik maka semakin tinggi porositas

\section{Pertambahan Jumlah Daun (Helai)}

Hasil pengamatan terhadap pertambahan jumlah pelepah tanaman kelapa sawit dengan pemberian kompos tandan kosong kelapa sawit dan pupuk NPK 16:16:16 setelah dilakukan analisis sidik ragam memperlihatkan bahwa pengaruh inreraksi dan pengaruh utama 
pemberian kompos tandan kosong kelapa sawit dan NPK 16:16:16 berpengaruh nyata terhadap pertambahan jumlah pelepah tanaman kelapa
sawit.Hasil uji beda nyata jujur (BNJ) pada taraf 5\% dapat dilihat pada tabel 2.

Tabel 2.Rata-rata pertambahan jumlah pelepah tanaman kelapa sawitdengan perlakuan kompos tandan kosong kelapa sawit dan pupuk NPK 16:16:16

\begin{tabular}{llcccc}
\hline \multirow{2}{*}{$\begin{array}{c}\text { KOMPOS } \\
\text { (gr/tanaman) }\end{array}$} & \multicolumn{4}{c}{ PUPUK NPK 16:16:16 (gr/tanaman) } & \multirow{2}{*}{ Rata-rata } \\
\cline { 2 - 5 } & $(15)$ & P2 & P3 & P4 & $(60)$ \\
\hline K0 $(0)$ & $2,67 \mathrm{e}$ & $3,50 \mathrm{cde}$ & $4,00 \mathrm{abc}$ & $4,17 \mathrm{abc}$ & $3,58 \mathrm{c}$ \\
K1 $(90)$ & $3,17 \mathrm{de}$ & $3,83 \mathrm{bcd}$ & $4,33 \mathrm{abc}$ & $4,50 \mathrm{abc}$ & $3,96 \mathrm{~b}$ \\
K2 $(180)$ & $3,83 \mathrm{bcd}$ & $4,00 \mathrm{abc}$ & $4,67 \mathrm{ab}$ & $4,83 \mathrm{ab}$ & $4,33 \mathrm{ab}$ \\
K3 $(270)$ & $4,00 \mathrm{abc}$ & $4,67 \mathrm{ab}$ & $5,00 \mathrm{a}$ & $4,00 \mathrm{abc}$ & $4,42 \mathrm{a}$ \\
\hline Rata-rata & $3,42 \mathrm{c}$ & $4,00 \mathrm{bc}$ & $4,50 \mathrm{ab}$ & $4,38 \mathrm{a}$ & \\
\hline
\end{tabular}

Angka-angka pada kolom dan baris yang diikuti huruf kecil yang sama tidak berbeda nyata menurut uji lanjut BNJ pada taraf 5\%.

Data pada tabel 3menunjukkan bahwa interaksi pemberian kompos tandan kosong kelapa sawit dan pupuk NPK 16:16:16 berpengaruh nyata terhadap pertambahan jumlah pelepah bibit kelapa sawit pada umur 3 bulan setelah pindah tanam. Jika dilihat dari hasil penelitian Gunawan (2017) pada penelitian sebelumnya di prenursery interaksi kombinasi perlakuan Kompos tandan kosong kelapa sawit 150 gr/tanaman dan Pemberian pupuk NPK 16:16:16 10 gr/tanaman (S3P2) juga merupakan kombinasi perlakuan terbaik. Hal ini disebabkan karena kombinasi perlakuan tersebut mampu memenuhi kebutuhan hara tanaman

Hal ini juga memperlihatkan bahwa penambahan kompos TKKS pada media dapat meningkatkan pertambahan jumlah pelepah tanaman, ditambah lagi dengan pemberian pupuk NPK 16:16:16, sehingga mampu menyediakan unsur hara yang cukup bagi tanaman terutama unsur $\mathrm{N}$ dan $\mathrm{P}$ yang diperlukan tanaman dalam pembentukan daun, dimana unsur $\mathrm{N}$ dan $\mathrm{P}$ pada media membantu proses pembelahan dan pembesaran sel yang menyebabkan daun muda lebih cepat mencapai bentuk yang sempurna, dimana semakin besar jumlah daun yang terbentuk pada tanaman, maka akan menghasilkan hasil fotosintat yang besar pula, dan hasil fotosintesis ini digunakan untuk pertumbuhan dan perkembangan tanaman. Sesuai dengan pendapat Lakitan (2007), bahwa ketersediaan unsur $\mathrm{N}$ dan $\mathrm{P}$ akan dapat mempengaruhi daun dalam hal bentuk dan jumlah. Hakim et al., (1989) menyatakan bahwa salah satu organ yang berperan penting bagi tanaman adalah daun. Jumlahnya sangat menentukan hasil fotosintesis, dimana hasil fotosintesis ini akan mempengaruhi pertumbuhan dan perkembangan tanaman.

\section{Pertambahan Panjang Pelepah Terpanjang(cm)}

Hasil pengamatan terhadap pertambahan panjang pelepah terpanjang tanaman kelapa sawit dengan pemberian kompos tandan kosong kelapa sawit dan pupuk NPK 16:16:16 setelah dilakukan analisis sidik ragammemperlihatkan bahwa pengaruh inreraksi dan pengaruh utama pemberian kompos tandan kosong kelapa sawit dan NPK berpengaruh nyata terhadap pertambahan jumlah pelepah tanaman kelapa sawit. Hasil uji beda nyata jujur pada taraf $5 \%$ dapat dilihat pada tabel 3.

Data pada tabel 3 menunjukkan bahwa pemberian kompos tandan kosong kelapa sawit dan pupuk NPK 16:16:16pada tanam kelapa sawit menunjukkan peningkatan terhadap panjang pelepah terpanjang, hal ini dapat dilihat antara kombinasi perlakuan tanpa pemberian kompos tandan kosong kelapa sawit dan pemberian pupuk NPK 16:16:16 (K0P1) dengan pemberian kompos tandan kosong kelapa sawit 270 gr/tanamandan pemberian pupuk NPK 16:16:16 60 gr/tanaman (K3P4), terjadi peningkatan panjang pelepah terpanjang sebesar $13.83 \mathrm{~cm}$. Hal ini menunjukkan bahwa pemberian kompos Tandan kosong kelapa sawit dan pupuk NPK 16:16:16 pada medium sub soil 
ultisol dapat memperbaiki sifat kimia, fisika dan biologi tanah.Bahan organik dapat menyumbangkan dan membantu menyediakan unsur-unsur hara bagi tanaman.Selain itu, penambahan bahan organik juga menyebabkan pori-pori tanah menjadi lebih baik sehingga sirkulasi udara yang dihasilkan cukup baik serta memiliki daya serap air yang tinggi. Sementara pupuk NPK 16:16:16 dapat menyumbangkan unsur hara yang dibutuhkan oleh tanaman untuk pertumbuhannya.

Tabel 3. Rata-rata pertambahan panjang pelepah terpanjang denganperlakuan kompos tandan kosong kelapa sawit dan pupuk NPK 16:16:16.

\begin{tabular}{|c|c|c|c|c|c|}
\hline \multirow{2}{*}{$\begin{array}{c}\text { KOMPOS } \\
\text { (gr/tanaman) }\end{array}$} & \multicolumn{4}{|c|}{ PUPUK NPK 16:16:16 (gr/tanaman) } & \multirow[b]{2}{*}{ Rata-rata } \\
\hline & $\begin{array}{l}\text { P1 } \\
(15)\end{array}$ & $\begin{array}{c}\text { P2 } \\
(30)\end{array}$ & $\begin{array}{c}\text { P3 } \\
(45) \\
\end{array}$ & $\begin{array}{c}\mathrm{P} 4 \\
(60)\end{array}$ & \\
\hline $\mathrm{K} 0(0)$ & $28,17 \mathrm{~g}$ & $29,17 \mathrm{fg}$ & 31,33 efg & $31,83 \mathrm{ef}$ & $30,13 \mathrm{~d}$ \\
\hline K1 (90) & 30,67 efg & 31,50 efg & 32,17 ef & $32,67 \mathrm{de}$ & $31,75 \mathrm{c}$ \\
\hline K2 (180) & 33,33 cde & $36,00 \mathrm{bcd}$ & $36,00 \mathrm{bcd}$ & $36,83 \mathrm{~b}$ & $35,54 \mathrm{~b}$ \\
\hline K3 (270) & $36,17 \mathrm{bc}$ & $37,17 \mathrm{~b}$ & $41,00 \mathrm{a}$ & $42,00 \mathrm{a}$ & $39,08 \mathrm{a}$ \\
\hline Rata-rata & $32,08 \mathrm{c}$ & $33,46 \mathrm{~b}$ & $35,13 \mathrm{a}$ & $35,83 \mathrm{a}$ & \\
\hline \multicolumn{6}{|c|}{$\mathrm{KK}=3,27 \% \mathrm{BNJ} \mathrm{N} \& \mathrm{P}=1,24 \mathrm{BNJ} \mathrm{N} \& \mathrm{P}=3,39$} \\
\hline
\end{tabular}

Angka-angka pada kolom dan baris yang diikuti huruf kecil yang sama tidak berbeda nyata menurut uji lanjut BNJ pada taraf $5 \%$.

Lingga dan Marsono (2001) mengatakan Pertambahan pertumbuhan tanaman sangat erat kaitannya dengan unsur hara makro seperti nitrogen, fosfor dan kalium.Penambahan unsur hara nitrogen dapat merangsang pertumbuhan vegetatif yakni cabang, batang dan daun yang merupakan komponen penyusun asam amino, protein dan pembentuk protoplasma sel yang dapat berfungsi dalam merangsang pertumbuhan tanaman.Fosfor merupakan komponen utama asam nukleat, berperan terhadap pembelahan sel pada titik tumbuh yang berpengaruh pada tinggi tanaman.Selain nitrogen dan fosfor unsur kalium juga berperan meningkatkan pertumbuhan tanaman yang berperan sebagai aktifator berbagai enzim.Hal ini sesuai dengan pendapat lakitan (2007) menyatakan bahwa tanaman yang tidak mendapatkan tambahan nitrogen akan tumbuh kerdil serta daun yang terbentuk juga lebih kecil, tipis dan jumlah nya akan sedikit, sedangkan tanaman yang mendapat tambahan unsur hara nitrogen maka daun yang terbentuk akan lebih banyak dan lebar, karena unsur hara yang paling berpengaruh terhadap pertumbuhan dan perkembangan daun adalah nitrogen. Kandungan $\mathrm{N}$ yang terdapat dalam tanaman akan dimanfaatkan tanaman dalam pembesaran sel. Pembelahan oleh sel-sel muda akan membentuk primordial daun.

\section{Pertambahan Lilit Batang (cm)}

Hasil pengamatan terhadap pertambahan lilit batang tanaman kelapa sawit dengan pemberian kompos tandan kosong kelapa sawit dan pupuk NPK setelah dilakukan analisis sidik ragammemperlihatkan bahwa pengaruh inreraksi dan pengaruh utama pemberian kompos tandan kosong kelapa sawit dan NPK berpengaruh nyata. Hasil uji beda nyata jujur (BNJ) pada taraf 5\% dapat dilihat pada tabel 4 .

Data pada tabel 4 menunjukkan bahwaPeningkatan kompos kompos tandan kosong kelapa sawit mampu memberikan pertumbuhan (bonggol) bibit kelapa sawit dengan baik, hal ini dikarenakan kandungan unsur haranya semakin banyak, sehingga memberikan pertumbuhan yang optimal pada bibit kelapa sawit.Kompos TKKS juga mampu memperbaiki sifat fisika, kimia dan biologi tanah. Jika diberikan dalam jumlah banyak maka akan semakin baik dalam memperbaiki kesuburan tanah., sehingga dengan pemberian perlakuan NPK 16:16:16 dapat saling menunjang untuk memenuhi kebutuhan tanaman, hasilnya unsur hara $\mathrm{N}, \mathrm{P}$ dan $\mathrm{K}$ yang diberikan dapat diserap bibit kelapa sawit dalam pembentukan bonggol. Menurut Hakimet al., (1986) menyatakan bahwa nitrogen, fosfor, dan kalium merupakan faktor pembatas karena pengaruhnya nyata bagi tanamanserta merupakan unsur hara yang paling banyak 
jumlahnya dibutuhkan tanaman. Pembesaran lingkar batang dipengaruhi oleh ketersediaan unsur kalium, kekurangan unsur ini menyebabkan terhambatnya proses pembesaran lingkar batang.Hal ini sesuai dengan pendapat Suryanti (2004), bahwa tersedianya unsur hara dalam jumlah yang cukup menyebabkan kegiatan metabolisme dari tanaman akan meningkat demikian juga akumulasi assimilate pada daerah batang akan meningkat sehingga terjadi pembesaran pada bagian batang.

Tabel 4. Rata-rata pertambahan lilit batang denganperlakuan kompos tandan kosong kelapa sawit dan pupuk NPK 16:16:16.

\begin{tabular}{|c|c|c|c|c|c|}
\hline \multirow{2}{*}{$\begin{array}{c}\text { KOMPOS } \\
\text { (gr/tanaman) }\end{array}$} & \multicolumn{4}{|c|}{ PUPUK NPK 16:16:16 (gr/tanaman) } & \multirow[b]{2}{*}{ Rata-rata } \\
\hline & $\begin{array}{l}\text { P1 } \\
(15)\end{array}$ & $\begin{array}{c}\text { P2 } \\
(30) \\
\end{array}$ & $\begin{array}{c}\text { P3 } \\
(45) \\
\end{array}$ & $\begin{array}{l}\text { P4 } \\
(60) \\
\end{array}$ & \\
\hline K0 (0) & $6,42 \mathrm{~d}$ & $8,33 \mathrm{bc}$ & $8,37 \mathrm{bc}$ & $9,17 \mathrm{abc}$ & $8,07 \mathrm{c}$ \\
\hline K1 (90) & $8,02 \mathrm{c}$ & $8,68 \mathrm{abc}$ & $8,90 \mathrm{abc}$ & $9,28 \mathrm{abc}$ & $8,72 \mathrm{~b}$ \\
\hline K2 (180) & $8,83 \mathrm{abc}$ & $9,02 \mathrm{abc}$ & $9,38 \mathrm{abc}$ & $9,45 \mathrm{ab}$ & $9,17 \mathrm{ab}$ \\
\hline K3 (270) & $8,93 \mathrm{abc}$ & $9,38 \mathrm{abc}$ & $9,92 \mathrm{a}$ & $9,43 \mathrm{ab}$ & $9,42 \mathrm{a}$ \\
\hline Rata-rata & $8,05 \mathrm{~b}$ & $8,85 \mathrm{a}$ & $9,14 \mathrm{a}$ & $9,33 \mathrm{a}$ & \\
\hline \multicolumn{6}{|c|}{$\mathrm{KK}=5,15 \% \mathrm{BNJ} \mathrm{N} \& \mathrm{P}=0,50 \mathrm{BNJ} \mathrm{N} \& \mathrm{P}=1,38$} \\
\hline
\end{tabular}

Angka-angka pada kolom dan baris yang diikuti huruf kecil yang sama tidak berbeda nyata menurut uji lanjut BNJ pada taraf $5 \%$.

Suriadikarta dan Adimihardja (2001) mengatakan bahwa nitrogen, fosfor dan kalium di dalam tanah ketersediaannya terbatas untuk pertumbuhan tanaman, oleh karena itu perlu dilakukan pemupukan. Salah satu bahan sebagai pupuk adalah tandan kosong kelapa sawit dan pupuk NPK 16:16:16 yang mengandung unsur hara makro dan mikro. Kompos tandan kosong kelapa sawit dan pupuk NPK 16:16:16 mengandung unsur hara makro dan mikro yang secara langsung akan meningkatkan proses fisologi dan metabolisme tanaman, hal ini akan mendorong untuk membentuk sel-sel baru sehingga berpengaruh pembentukan jaringan tanaman yaitu akar, batangdan daun serta secara langsung akan mempengaruhi diameter bonggol bibit kelapa sawit.

\section{Jumlah Akar Primer (Buah)}

Hasil pengamatan terhadap jumlah akar primer tanaman kelapa sawit dengan pemberian kompos tandan kosong kelapa sawit dan pupuk NPK 16:16:16 setelah dilakukan analisis sidik ragam memperlihatkan bahwa pengaruh inreraksi pemberian kompos tandan kosong kelapa sawit dan NPK tidak berpengaruh nyata terhadap jumlah akar primer tanaman kelapa sawit. Namun pengaruh utama masing masing faktor pelakuan berpengaruh nyata terhadap jumlah akar primer tanaman kelapa sawit.Hasil uji beda nyata jujur (BNJ) pada taraf 5\% dapat dilihat pada tabel 5 .

Tabel 5. Rata-ratajumlah akar primer denganperlakuan kompos tandan kosong kelapa sawit dan pupuk NPK 16:16:16.

\begin{tabular}{cccccc}
\hline \multirow{2}{*}{$\begin{array}{c}\text { KOMPOS } \\
\text { (gr/tanaman) }\end{array}$} & $\mathrm{P} 1$ & $\mathrm{P} 2$ & $\mathrm{P} 3$ & $\mathrm{P} 4$ & Rata-rata \\
\cline { 2 - 4 } & $(15)$ & $(30)$ & $(45)$ & $(60)$ & \\
\hline K0 (0) & 15,00 & 15,67 & 16,33 & 17,00 & $16,00 \mathrm{~b}$ \\
K1 (90) & 17,00 & 17,67 & 18,00 & 18,33 & $17,75 \mathrm{~b}$ \\
K2 $(180)$ & 18,33 & 18,67 & 19,00 & 20,00 & $19,00 \mathrm{ab}$ \\
K3 (270) & 20,33 & 20,67 & 21,00 & 23,33 & $21,33 \mathrm{a}$ \\
\hline Rata-rata & $17,67 \mathrm{~d}$ & $18,17 \mathrm{c}$ & $18,58 \mathrm{~b}$ & $19,67 \mathrm{a}$ \\
\hline \multicolumn{5}{c}{$\mathrm{KK}=$} & $5,15 \%$ BNJ N\&P=1,14 \\
\hline
\end{tabular}

Angka-angka pada kolom dan baris yang diikuti huruf kecil yang sama tidak berbeda nyata menurut uji lanjut BNJ pada taraf $5 \%$. 
Data pada tabel 6 menunjukkan bahwa

Jumlah akar primer terbanyak didapat pada perlakuan kompos tandan kosong kelapa sawit 270 gr/tanaman (K3), hal ini diduga karena dengan pemberian kompos tandan kosong kelapa sawit dapat memperbaiki sifat fisik tanah, Selain itu Pemberian bahan organik seperti kompos tandan kosong kelapa sawit pada medium tumbuh tanaman sangatlah baik karena dapat meningkatkan daya serap serta daya ikat tanah terhadap air dan unsur hara yang merupakan faktor untuk perkembangan akar. Hal ini sesuai dengan pendapat Lingga (1991) bahwa bahan organik mampu memperbaiki struktur tanah dengan membentuk butiran tanah yang lebih besar oleh senyawa perekat yang dihasilkan mikroorganisme yang terdapat pada bahan organik. Butiran tanahtanah yang lebih besar akan memperbaiki permeabilitas dan agregat tanah sehingga daya serap serta daya ikat tanah terhadap air akan meningkat.

Sutejo (2002) menyatakan bahwa pemberian pupuk organik dapat meningkatkan aktifitas jasad tanah dan mempertinggi daya serap tanah terhadap unsur hara yang tersedia, karena struktur tanah menjadi meningkat sehingga akar dapat menyerap unsur hara dengan baik.Jika pemberian pupuk organik tidak optimal maka tanaman dapat terganggu dalam melakukan aktifitasnya dan hal ini menyebabkan tanaman tidak dapat tumbuh dan berkembang dengan baik.

\section{Panjang Akar (cm)}

Hasil pengamatan terhadap panjang akar tanaman kelapa sawit dengan pemberian kompos tandan kosong kelapa sawit dan pupuk NPK 16:16:16 setelah dilakukan analisis sidik ragammemperlihatkan bahwa pengaruh inreraksi pemberian kompos tandan kosong kelapa sawit dan NPK 16:16:16 tidak berpengaruh nyata terhadap panjang akar tanaman kelapa sawit. Namun pengaruh utama masing masing faktor pelakuan berpengaruh nyata terhadap panjang akar tanaman kelapa sawit. Hasil uji beda nyata jujur (BNJ) pada taraf 5\% dapat dilihat pada tabel 6 .

Tabel 6.Rata-rata panjang akar denganperlakuan kompos tandan kosong kelapa sawit dan pupuk NPK 16:16:16.

\begin{tabular}{cccccc}
\hline \multirow{2}{*}{$\begin{array}{c}\text { KOMPOS } \\
\text { (gr/tanaman) }\end{array}$} & $\mathrm{P} 1$ & $\mathrm{P} 2$ & $\mathrm{P} 3$ & $\mathrm{P} 4$ & Rata-rata \\
\cline { 2 - 4 } & $(15)$ & $(30)$ & $(45)$ & $(60)$ & \\
\hline K0 (0) & 58,00 & 60,67 & 61,67 & 65,00 & $61,33 \mathrm{c}$ \\
K1 (90) & 64,33 & 65,00 & 65,00 & 71,33 & $66,42 \mathrm{~b}$ \\
K2 (180) & 66,67 & 68,33 & 71,33 & 76,00 & $70,58 \mathrm{~b}$ \\
K3 (270) & 71,00 & 78,00 & 81,33 & 84,00 & $78,58 \mathrm{a}$ \\
\hline Rata-rata & $65,00 \mathrm{c}$ & $68,00 \mathrm{bc}$ & $69,83 \mathrm{ab}$ & $74,08 \mathrm{a}$ & \\
\hline \multicolumn{7}{c}{$\mathrm{KK}=$} & $5,87 \%$ BNJ N\&P=4,51
\end{tabular}

Angka-angka pada kolom dan baris yang diikuti huruf kecil yang sama tidak berbeda nyata menurut uji lanjut BNJ pada taraf 5\%.

Panjang akar terpanjang didapat pada perlakuan kompos tandan kosong kelapa sawit $270 \mathrm{gr} / \operatorname{tanaman}$ (K3), hal ini diduga karena terpenuhinya unsur hara pada perlakuan ini, sesuai dengan pendapat Pahan (2010) Pertumbuhan akar dan percabangan akar dapat terangsang bila konsentrasi hara dalam tanah seperti P cukup besar. Diduga bahwa kandungan $\mathrm{P}$ pada kompos tandan kosong kelapa sawit dapat mencukupi kebutuhan hara akar tanaman sehingga perakaran bibit berkembang dengan baik.Akar merupakan bagian penting dalam pertumbuhan tanaman yang mencerminkan kemampuan dalam penyerapan unsur hara serta metabolisme yang terjadi pada tanaman.Lakitan (2007) menyatakan bahwa sebagian besar unsur yang dibutuhkan tanaman diserap dari larutan tanah melalui akar, kecuali karbon dan oksigen yang diserap dari udara oleh daun. Menurut Sarief (1986) jika perakaran tanaman berkembang dengan baik, pertumbuhan bagian tanaman lainnya akan baik juga karena akar mampu menyerap air dan unsur hara yang dibutuhkan oleh tanaman. 
Sedangkan panjang akar terpendek didapat dari perlakuan K0 (Kompos tandan kosong kelapa sawit 0gr / tanaman) dengan Rata-rata panjang akar tanaman kelapa sawit yaitu $61.33 \mathrm{~cm}$. perlakuan K0 berbeda nyata dengan perlakuan lainnya. Pendeknya panjang akar pada perlakuan ini disebabkan oleh pada perlakuan tersebut tidak dilakukan pemberian kompos tandan kosong kelapa sawit yang menyebabkan stuktur tanah lebih padat sehingga perkembangan akar terganggu. Bariantoet al., (2010) mengatakan Penggunaan bahan organik atau kompos sangat baik karena dapat memberikan manfaat baik bagi tanah maupun tanaman. Bahan organik atau kompos selain menambah unsur hara pada tanah juga dapat menggemburkan tanah, memperbaiki struktur dan porositas tanah, meningkatkan daya ikat tanah terhadap air dan menyimpan air lebih lama sehingga tanaman dapat tumbuh dengan normal.

\section{KESIMPULAN DAN SARAN}

\section{Kesimpulan}

Berdasarkan hasil penelitian dapat disimpulkan sebagai berikut :

1. Interaksi pemberian kompos tandan kosong kelapa sawit dan pupuk NPK 16:16:16 memberikan pengaruh nyata terhadap pertambahan tinggi tanaman, pertambahan jumlah pelepah, pertambahan panjang pelepah terpanjang dan pertambahan lilit batang. Kombinasi perlakuan terbaik pada pemberian kompos tandan kosong kelapa sawit $270 \mathrm{gr} / \mathrm{tanaman}$ dan pupuk NPK 16:16:16 $60 \mathrm{gr} / \operatorname{tanaman}$ (K3P4).

2. Pengaruh utama pemberian kompos tandan kosong kelapa sawit memberikan pengaruh nyata terhadap semua parameter yang dimati yaitu pertambahan tinggi tanaman, pertambahan jumlah pelepah, pertambahan panjang pelepah terpanjang, pertambahan lilit batang, jumlah akar primer dan panjang akar terpanjang. Dengan perlakuan terbaik yaitu pemberian kompos tandan kosong kelapa sawit $270 \mathrm{gr} / \operatorname{tanaman}(\mathrm{K} 3)$.

3. Pengaruh utama pemberian pupuk NPK 16:16:16 memberikan pengaruh nyata terhadap semua parameter yang dimati, dengan perlakuan terbaik yaitu pemberian pupuk NPK 16:16:16 60 gr/tanaman (P4).

\section{Saran}

Dari hasil penelitian penulis menyarankan untuk melakukan penelitian lanjutan dengan pemberian dosis kompos tandan kosong kelapa sawit dan pupuk NPK16:16:16 yang lebih tinggi, karena hasil penelitian ini masih menunjukkan kemungkinan peningkatan pertumbuhan bibit kelapa sawit.

\section{DAFTAR PUSTAKA}

Fauzi, Y., Y.E. Widiastuti, I. Satyawibawa, dan R. Hartono. 2002. Kelapa Sawit. Edisi Revisi. Penebar Swadaya. Depok.Darnoko dan A. S. Sutarta.2006. Pabrik Kompos di Pabrik Sawit.Tabloid Sinar Tani. Jakarta.

Gunawan.2017. Uji pemberian tandan kosong kelapa sawit dan NPK 16:16:16 terhadap pertumbuhan bibit kelapa sawit (Elaeis Gueneensis jacq) Main- nursery dengan media subsoil ultisol. Skripsi (tidak dipublikasikan).Fakultas Pertanian Universitas Islam Riau.Pekanbaru.

Hakim., N. M. Y. Nyakpa, A. M. Lubis, S. G. Nugroho, M. R. Saul, M. A. Diha, G. B. Hong dan H. H. Bailey. 1986. DasarDasar Ilmu Tanah. Universitas Lampung. Bandar Lampung.

Lakitan,. B. 2007. Dasar-Dasar Fisiologi Tumbuhan. Raja Grafindo Persada. Jakarta

Lingga, P. 1991. Jenis Kandungan Hara pada Beberapa Kotoran Ternak.Pusat Penelitian Pertanian dan Pedesaan Swadaya (P4S).ANTANAN. Bogor.

Lingga, P. dan Marsono. 2001. Petunjuk Penggunaan Pupuk. Penebar Swadaya. Jakarta. $163 \mathrm{hlm}$.

Pahan, I. 2010. Panduan Lengkap Kelapa Sawit Manajemen Agribisnis dari Hulu Hingga Hilir. Penebar Swadaya. JakartaSarief, E. S., 1986. Ilmu Tanah Pertanian. Pustaka Buana, Bandung.

Suriadikarta, D. A. dan A. Adimihardja. 2001. Penggunaan Pupuk Dalam Rangka Peningkatan Produktivitas Lahan Sawah. 
Jurnal Litbang Pertanian, 29 (24): 144152.

Suryati, Y. 2004. Pengaruh Volume Tanah dan

Dosis Pupuk NPK terhadap Pertumbuhan

Kelapa Sawit Di Pembibitan

Utama.Skripsi (tidak

dipublikasikan).Fakultas Pertanian

Universitas Riau. Pekanbaru.

Sutejo, M. 2002. Pupuk dan Cara

Pemupukan.Rineka Cipta. Jakarta. 
